\title{
Assessing Malnourished Children between 0 - 5 Years of Age at the Bamenda Regional Hospital, Cameroon
}

\author{
Samuel Nambile Cumber ${ }^{1,2}$, Shalom Jaila ${ }^{2}$, Nancy Bongkiynuy ${ }^{2}$, Mercy Kein ${ }^{2}$, \\ Rosaline Yumumkah Kanjo-Cumber ${ }^{2,3}$ \\ ${ }^{1}$ Discipline of Public Health Medicine, Department of Nursing \& Public Health, College of Health Sciences, University of Kwazulu-Natal, \\ Durban, South Africa \\ ${ }^{2}$ Under Privileged Children and Women Assistance (UPCAWA-SWEDEN), Cameroon Branch, Bamenda, Cameroon \\ ${ }^{3}$ Department of Political Science, University of KwaZulu-Natal, Durban, South Africa
}

Email address:

samuelcumber@yahoo.com (S. N. Cumber)

\section{To cite this article:}

Samuel Nambile Cumber, Shalom Jaila, Nancy Bongkiynuy, Mercy Kein. Assessing Malnourished Children Between 0 - 5 Years of Age at the Bamenda Regional Hospital, Cameroon. Journal of Family Medicine and Health Care. Vol. 2, No. 4, 2016, pp. 51-56.

doi: $10.11648 /$ j.jfmhc.20160204.15

Received: August 24, 2016; Accepted: October 12, 2016; Published: November 3, 2016

\begin{abstract}
Assessing the lifestyle of malnourished children between 0-5 years of age at the Bamenda Regional Hospital. Our aim was to identify the lifestyles that predispose children to be malnourished and the most prevalent type of malnutrition. A descriptive cross sectional hospital-based study was carried out at the Bamenda Regional Hospital and included 20 respondents. A structured questionnaire was used for data collection which consisted of open and closed ended questions. Data was coded manually, entered into excel and exported into SPSS version 18 for analysis. The study revealed that the respondents turn to eat what they have (90.9\%) and what they feel as eating $(87.7 \%)$. $(27.3 \%)$ of the respondents who have knowledge on malnutrition practice nonexclusive breast feeding. We also discovered that $(55 \%)$ of the respondents weight for height 3.1-5 years of age have a height $65-85 \mathrm{~cm}$ indicating a drastic drop in height for weight. The study revealed that $25 \%$ wean their children at 6 months. $66.7 \%$ had no time to breastfeed their children. Our studies therefore reveal that the most prevalent type of malnutrition results due to predisposing lifestyle factors like low income, poor complementary feds and low levels of education.
\end{abstract}

Keywords: Lifestyle, Malnourish, Children, Bamenda

\section{Background}

Malnutrition is one of the major causes of morbidity in children which does not only Include acute effects on children health, but also it has long term effects on their cognitive development and economic growth in the society. $[1,2]$

In most cases, malnutrition is very mild and present with no symptoms. However, sometimes it can be so severe that the damage done to the body is permanent, although some died while others survived. [3] According to Olsen, about 35\% of all preschool children in developing countries are underweight [4]. According to him using the wasting scale, children with severe malnutrition have 8 times higher rate of mortality compared with children with moderate and mild malnutrition having 4 to 2 times higher rate of mortality. However, the high prevalence of mortality even in children with moderate and mild malnutrition indicates that more than $50 \%$ of mortalities in children are directly or indirectly due to malnutrition. [2, 3]

Malnutrition Continues to be a more significant problem all over the world, especially in children. [1, 3] Natural disasters, poverty, political problem and war all contribute to the conditions. $[1,3,5]$ Symptoms vary and depend on what is causing the malnutrition. [3,5] However, some general symptoms include fatigue, dizziness and weight loss. [1-3]

According to the world health organization, recent past crises have greatly affected the health status of children by 
causing severe diarrhoea, upper respiratory infections and the crises of shortage of food in which families do not have enough food. [6, 7]

Approximately 12 million children under 5 years mostly in developing countries die every year. [6] More than $50 \%$ of these deaths are attributed to diarrhoea, acute respiratory illness, malaria or measles, conditions that are either preventable or treatable with low cost interventions. [6, 7]

In most countries, malnutrition affects children under 5 and most government find it difficult to eradicate it. In the rural settings most health care services are inaccessible and so most children die due to lack of treatment thereby increasing mortality rate. $[6,7]$

Despite the effort and care some parents give to their children, some still became malnourish. It is wise to go out and look for the underlying life style which predisposes children to malnutrition.

The aim and focus behind this study is to assess malnourished children who are under five years of age as reports have shown that malnutrition is a burden and a cause of death for children bellow the age of 5 years. According to a study on humanities and social sciences, most parents feed their children with inadequate nutrients due to lack of knowledge and poverty in most low and middle income countries.

This study aims at contributing in reducing the risk of dying in children under five years in Cameroon. The objective was to investigate those factors that predispose children from 0-5 years of age to malnutrition; (to identify the most prevalent type of malnutrition; to identify the reasons for its occurrence; to identify habits that predispose children to malnutrition; to identify barriers of nutrition).

\section{Material and Methods}

The study population was made up of malnourished children $0-5$ years and those included were underweight children, with respondents being mothers or guidance of children under 5years of age and our sample size was 20 . This study was carried out at the Bamenda Regional Hospital from the $5^{\text {th }}$ of January to the $15^{\text {th }}$ of February 2015.

Participants were chosen using convenient purposive sampling approach. Samples of 20 respondents were recruited.

$$
\frac{(\mathrm{n}) 2=\mathrm{Z} \infty / 2 \mathrm{~S}}{\text { EMAX }}
$$

Where $\mathrm{n}=$ sample size

$$
\begin{gathered}
\mathrm{Z}_{\infty / 2}=\text { Maximum error } \\
\mathrm{S}=\text { Standard Deviation } \\
\mathrm{E}_{\mathrm{MAX}}=\text { Duration }
\end{gathered}
$$

A clearance form was obtained from the Head of Department of nursing after submission and approval of the research proposal by the supervisor, which permitted us to carry out our research in the clinical area. There was equally a permission from the medical director of the study area to carry out this work in the hospital. Authorization was obtained from Regional Delegation of Bamenda.

The interview consisted of structured questionnaires with open and closed ended questions. There was a consent form addressed to each respondent informing them about the research and that the responses were used purely for research purpose.

After administration of questionnaire information gotten was filed to maintain confidentiality and the data was saved in a flash and email box to prevent malware and only the group members could have access to it.

Data was coded manually, entered into excel and downloaded into SPSS version 18 for analysis and presented using tables and cross tabulation.

Strengths of the study

- This study will enable the interdisciplinary team during assessment to think of other underlying causes of malnutrition in children.

- It will enable the health team to educate the family and care givers on the importance of balance diet during pregnancy, peuperum and infant growth.

- It will also help the legal care givers and guidance of children to understand that economic and social factors contributes to malnutrition and so provision should be made when planning to have more children in a family.

By assessing the contributions of the various forms or types of malnutrition on health outcome health professionals and policy makers may be able to design programs and intervention to target this problem

\section{Presentation of Results}

From the table below, $(65.0 \%)$ of the respondents were female while $(35.0 \%)$ were males.

Table 1. Distribution of respondents according to sex.

\begin{tabular}{clll}
\hline Sex & Frequency & Percent (\%) \\
\hline Male & 7 & 35.0 \\
Female & 13 & 65.0 \\
Total & 20 & 100.0 \\
\hline
\end{tabular}

From the table below, majority of the children age $3.1-5$ have the height of $65-85 \mathrm{~cm}$ with a percentage of $60.0 \%$ while a minority age 0 - 1 have height of $40-50 \mathrm{~cm}$ with a percentage of $100 \%$. 
Table 2. Ross Tabulation of respondents according to Age and height.

\begin{tabular}{|c|c|c|c|c|c|c|}
\hline \multirow{2}{*}{ Age } & & \multicolumn{4}{|l|}{ Height } & \multirow{2}{*}{ Total } \\
\hline & & $40-50 \mathrm{~cm}$ & $50-65 \mathrm{~cm}$ & $65-85 \mathrm{~cm}$ & $>85 \mathrm{~cm}$ & \\
\hline \multirow{2}{*}{ 0-1 year } & $f$ & 1 & 0 & 0 & 0 & 1 \\
\hline & $(\%)$ & $100.0 \%$ & $.0 \%$ & $.0 \%$ & $.0 \%$ & $5.0 \%$ \\
\hline \multirow{2}{*}{$1.1-2$ years } & $\mathrm{f}$ & 0 & 2 & 1 & 0 & 3 \\
\hline & $(\%)$ & $.0 \%$ & $50.0 \%$ & $10.0 \%$ & $.0 \%$ & $15.0 \%$ \\
\hline \multirow{2}{*}{ 2.1-3 years } & f & 0 & 1 & 3 & 0 & 4 \\
\hline & $(\%)$ & $.0 \%$ & $25.0 \%$ & $30.0 \%$ & $.0 \%$ & $20.0 \%$ \\
\hline \multirow{2}{*}{$3.1-5$ years } & $\mathrm{f}$ & 0 & 1 & 6 & 5 & 12 \\
\hline & $(\%)$ & $.0 \%$ & $25.0 \%$ & $60.0 \%$ & $100.0 \%$ & $60.0 \%$ \\
\hline \multirow{2}{*}{ Total } & f & 1 & 4 & 10 & 5 & 20 \\
\hline & $(\%)$ & $100.0 \%$ & $100.0 \%$ & $100.0 \%$ & $100.0 \%$ & $100.0 \%$ \\
\hline
\end{tabular}

The table below, majority of the children age 3.1-5years have weight $4 \mathrm{~kg}-8 \mathrm{~kg}$ while Minority ages $0-1$ year have the weight $2.5-4 \mathrm{~kg}$.

Table 3. Cross Tabulation of respondents according to Weight and Age.

\begin{tabular}{|c|c|c|c|c|c|c|c|}
\hline \multirow{2}{*}{ Weight } & & & \multicolumn{4}{|l|}{ Age } & \multirow{2}{*}{ Total } \\
\hline & & & 0-1 year & 1.1-2 years & 2.1-3 years & 3.1- 5 years & \\
\hline \multirow{2}{*}{\multicolumn{2}{|c|}{$2.5-4 \mathrm{~kg}$}} & $\mathrm{f}$ & 1 & 0 & 0 & 0 & 1 \\
\hline & & $(\%)$ & $100.0 \%$ & $.0 \%$ & $.0 \%$ & $.0 \%$ & $5.0 \%$ \\
\hline \multirow{2}{*}{\multicolumn{2}{|c|}{$4 \mathrm{~kg}-8 \mathrm{~kg}$}} & $\mathrm{f}$ & 0 & 3 & 3 & 5 & 11 \\
\hline & & $(\%)$ & $.0 \%$ & $100.0 \%$ & $75.0 \%$ & $41.7 \%$ & $55.0 \%$ \\
\hline \multirow{2}{*}{\multicolumn{2}{|c|}{$8 \mathrm{~kg}-10 \mathrm{~kg}$}} & $\mathrm{f}$ & 0 & 0 & 1 & 3 & 4 \\
\hline & & $(\%)$ & $.0 \%$ & $.0 \%$ & $25.0 \%$ & $25.0 \%$ & $20.0 \%$ \\
\hline \multirow{2}{*}{\multicolumn{2}{|c|}{$10 \mathrm{~kg}-15 \mathrm{~kg}$}} & $\mathrm{f}$ & 0 & 0 & 0 & 4 & 4 \\
\hline & & $(\%)$ & $.0 \%$ & $.0 \%$ & $.0 \%$ & $33.3 \%$ & $20.0 \%$ \\
\hline \multirow{2}{*}{\multicolumn{2}{|c|}{ Total }} & $\mathrm{f}$ & 1 & 3 & 4 & 12 & 20 \\
\hline & & $(\%)$ & $100.0 \%$ & $100.0 \%$ & $100.0 \%$ & $100.0 \%$ & $100.0 \%$ \\
\hline
\end{tabular}

From the table below, a majority of the children $(\mathrm{f}=11)$ have weight range of $4 \mathrm{Kg}$ to $8 \mathrm{~kg}$ with a majority of the children $(\mathrm{f}=10$ ) equally have a height range $65 \mathrm{~cm}$ to $85 \mathrm{~cm}$.

Table 4. Cross tabulation of respondents according to Weight and Height.

\begin{tabular}{|c|c|c|c|c|c|}
\hline \multirow{2}{*}{ Weight } & \multicolumn{4}{|l|}{ Height } & \multirow{2}{*}{ Total } \\
\hline & $40-50 \mathrm{~cm}$ & $50-65 \mathrm{~cm}$ & $65-85 \mathrm{~cm}$ & $>85 \mathrm{~cm}$ & \\
\hline $2.5-4 \mathrm{~kg}$ & 1 & 0 & 0 & 0 & 1 \\
\hline $4 \mathrm{~kg}-8 \mathrm{~kg}$ & 0 & 4 & 5 & 2 & 11 \\
\hline $8 \mathrm{~kg}-10 \mathrm{~kg}$ & 0 & 0 & 4 & 0 & 4 \\
\hline $10 \mathrm{~kg}-15 \mathrm{~kg}$ & 0 & 0 & 1 & 3 & 4 \\
\hline Total & 1 & 4 & 10 & 5 & 20 \\
\hline
\end{tabular}

From the table below, $(77.8 \%)$ of the respondents who have no knowledge on malnutrition claim to practice exclusive breast feeding while $(72.7 \%)$ of respondents who have no knowledge on malnutrition practice nonexclusive breast feeding.

Table 5. Cross tabulation of respondents according to knowledge on malnutrition and method of breast feeding.

\begin{tabular}{cllll}
\hline $\begin{array}{c}\text { Do you have knowledge on } \\
\text { malnutrition? }\end{array}$ & \multicolumn{2}{l}{ What method of breast feeding do you practice? } & Total \\
\cline { 2 - 5 } & Exclusive breast feeding & Nonexclusive breast feeding & 5 \\
\hline \multirow{2}{*}{ Yes } & F & 2 & 3 & $25.0 \%$ \\
& $(\%)$ & $22.2 \%$ & $27.3 \%$ & 15 \\
No & F & 7 & 8 & $75.0 \%$ \\
\hline
\end{tabular}

From the table below, a majority of the respondents weaned their children at the ages 2 and 4 months (25\%). A majority of those who wean their children at six months (50\%) are business people. 
Table 6. Cross tabulation of respondents according to Occupation of mother and When baby is wean.

\begin{tabular}{|c|c|c|c|c|c|c|}
\hline \multirow{2}{*}{\multicolumn{2}{|c|}{ Occupation }} & \multicolumn{5}{|c|}{ When did you wean your baby? } \\
\hline & & Missing value & Six months & Two months & Nine months & Four months \\
\hline \multirow{2}{*}{ Business } & $\mathrm{F}$ & 1 & 2 & 1 & 0 & 0 \\
\hline & $(\%)$ & $25.0 \%$ & $50.0 \%$ & $25.0 \%$ & $.0 \%$ & $.0 \%$ \\
\hline \multirow{2}{*}{ Farmer } & $\mathrm{F}$ & 2 & 0 & 1 & 1 & 0 \\
\hline & $(\%)$ & $50.0 \%$ & $.0 \%$ & $25.0 \%$ & $25.0 \%$ & $.0 \%$ \\
\hline \multirow{2}{*}{ Civil servant } & $\mathrm{F}$ & 0 & 0 & 0 & 0 & 1 \\
\hline & $(\%)$ & $.0 \%$ & $.0 \%$ & $.0 \%$ & $.0 \%$ & $100.0 \%$ \\
\hline \multirow{2}{*}{ other } & $\mathrm{F}$ & 0 & 2 & 3 & 2 & 4 \\
\hline & $(\%)$ & $.0 \%$ & $18.2 \%$ & $27.3 \%$ & $18.2 \%$ & $36.4 \%$ \\
\hline \multirow{2}{*}{ Total } & $\mathrm{F}$ & 3 & 4 & 5 & 3 & 5 \\
\hline & $(\%)$ & $15.0 \%$ & $20.0 \%$ & $25.0 \%$ & $15.0 \%$ & $25.0 \%$ \\
\hline
\end{tabular}

From the table below, (90.9\%) of the respondents with income less than 10,000 FCFA a month eat what they have while $(12.5 \%)$ of those who earn 50.000-90.000 FCFA a month also eat what they feel like eating.

Table 7. Cross tabulation of respondents according to Income per month and frequency of food intake.

\begin{tabular}{cllll}
\hline \multirow{2}{*}{ Income per month } & & What and when do you eat? & What I feel like eating \\
\cline { 3 - 5 } & & What I have & Balanced diet & 7 \\
\multirow{2}{*}{$<10,000$} & $\mathrm{~F}$ & 10 & 1 & $87.5 \%$ \\
\multirow{2}{*}{$50,000-$} & $(\%)$ & $90.9 \%$ & $100.0 \%$ & 1 \\
90,000 & $\mathrm{~F}$ & 1 & 0 & $12.5 \%$ \\
\multirow{2}{*}{ Total } & $(\%)$ & $9.1 \%$ & $.0 \%$ & 8 \\
& $\mathrm{~F}$ & 11 & 1 & $100.0 \%$ \\
\hline
\end{tabular}

From the table below, $(86.7 \%)$ of respondents breast fed their children on demand and gave the first breast milk to them and $(13.3 \%)$ of the respondents Breast fed their babies on demand but did not give the first breast milk to their children.

Table 8. Cross tabulation of respondents according to first breast milk intake and frequency of breast milk.

\begin{tabular}{clllll}
\hline \multirow{2}{*}{$\begin{array}{c}\text { Do you give first breast milk to } \\
\text { your child? }\end{array}$} & \multicolumn{4}{l}{ When do you breastfeed your baby? } \\
\cline { 3 - 6 } & & No answer & On demand & When I like & 5 times a day \\
\hline \multirow{2}{*}{ Yes } & F & 0 & 13 & 1 & 0 \\
& $(\%)$ & $.0 \%$ & $86.7 \%$ & $50.0 \%$ & $.0 \%$ \\
\multirow{2}{*}{ No } & F & 1 & 2 & 1 & 2 \\
& $(\%)$ & $100.0 \%$ & $13.3 \%$ & $50.0 \%$ & $100.0 \%$ \\
\multirow{2}{*}{ Total } & F & 1 & 15 & 2 & 2 \\
& $(\%)$ & $100.0 \%$ & $100.0 \%$ & $100.0 \%$ & $100.0 \%$ \\
\hline
\end{tabular}

From the table below $(66.7 \%)$ of the respondents said they had no time while(33.3\%) said colostrum belongs to the gods.

Table 9. Distribution of respondents according to reasons for not First breast milk intake.

\begin{tabular}{lll}
\hline Reasons for not giving first breast milk to child & Frequency & Total \\
\hline Belongs to the gods & 2 & $33.3 \%$ \\
No time & 4 & $66.7 \%$ \\
Total & 6 & $100 \%$ \\
\hline
\end{tabular}

\section{Discussion}

In this study, among the 20 collaborative respondents $35.0 \%$ were males, while $65.0 \%$ were females, (table 1 ). This result is in line with that obtained by the National Health Survey II cited in Gragnotali, where under nutrition among girls was $54.8 \%$ which exceeded those of the boys $46.8 \%$ [7].

Based on the knowledge on malnutrition and method of breast feeding practiced seven respondents who have no knowledge on malnutrition claim to practice exclusive breast feeding while majority of the respondents eight who have no knowledge on malnutrition practice nonexclusive breast feeding (table. 5). This result is not in line with studies by
Pelletier and colleagues, who stated that mothers who are educated are less likely to have children who suffer from acute malnutrition [8].

With regards to the first breast milk given to children in (table.8), 86.7\% of the respondents breast fed their children on demand and gave the first breast milk to them and $13.3 \%$ breast fed their babies on demand but did not give the first breast milk to their children because it belongs to the witches which is in conformity with Christian $\mathrm{P}$, whose findings identify colostrums as witch's milk [1].

From results obtain based on maternal educational level (75.0\%) of the respondents were not educated while $(25.0 \%)$ of the respondents were educated and had knowledge on malnutrition which is in conformity with studies by Garcia 
and Alderman [9], who said mothers who are more educated are less likely to have children who suffer from malnutrition, (Table. 5).

From our result obtain based on the level of income, households with income level less than 10.000FCFA per month have a greater percentage of malnourished children which ties with National Family Survey [7], which reports that an increase in under nutrition among children belonging to households with low standard of living is twofold more than with high standard of living, (Table. 7).

Haddad studies show that large family, inadequate dietary intake, contributes to under nutrition among low income group which is in line with our studies where majority of the respondents turn to eat what they have and what they feel as eating and not balance diet (Table.7) [10].

The National Family Health Survey [7], reports that an increase in under nutrition among children belonging to households with low standard of living is twofold more than with high standard of living which is in line with studies with Haddad [10], which shows that large family, inadequate dietary intake, contributes to under nutrition among low income group.

While the National Family Health Survey and reports from Haddad dwell on low standards of living, low income and large family as causes of malnutrition, National Diet and Nutrition survey published in 1995 contradicts by saying nutritional intake habits of children is one of major causes of malnutrition since they turn to consume particular diets [7, 10-12].

From the results obtained based on weaning and initiation of complementary feeds early weaning 2 months, 4 months and initiation of complementary feeds predispose children to malnutrition which is in accordance with studies by Desphande [13], which states that feeding practice changes with age. This can be attributed to insufficient amount of complementary feeds in the later months, late weaning and early initiation of complementary feeds in the earlier months, (Table. 6).

From our studies, children with the weight range of $4 \mathrm{~kg}$ $8 \mathrm{~kg}$ have the height of $50-85 \mathrm{~cm}$ which is in contrast with the normal weight for height (53.5-66.0).

Our studies also show that children with age 3.1-5 years have the weight $4-8 \mathrm{~kg}$ which is also in contrast with the normal weigh for age where by, children age 3.1-5 years has a normal weight of $11.8-23.8 \mathrm{~kg}$.

Moreover, children of age 3.1-5years have the height range of $65-85 \mathrm{~cm}$ which is directly in contrast with the normal height for age where in, children of the same age group have the height $87.6-116.5 \mathrm{~cm}$.

\section{Conclusion}

This study found out that the most prevalent type of malnutrition is moderate. Despite the availability of food in our society today, there is lack of knowledge on nutrition, importance of breast feeding and family planning these factors together with poverty are lifestyle factors that predispose the under 5 years to malnutrition since most families turn to eat what they have and what they like.

\section{Recommendations}

This study recommend that in order to overcome malnutrition in children 0-5years public health authorities should be informed through the medical officers to organize refresher courses for nurses, parents, guidance on the importance of nutrition according to the WHO guidelines for children.

Nurses and midwives should make emphases during antenatal clinic and infant welfare clinics on good nutrition for both mother and child. Exclusive breast feeding should be stressed, appropriates weaning period should be emphasized also colostrums should be encourage because it boast the immunity and is balanced and so prevents infections which predispose children to malnutrition.

Most parturient for fear of caesarean section and perinea taers turn to starve themselves and so become underweight and there after give birth to low birth weight infants which predispose them to malnutrition thus pregnant women should be well followed up during antenatal clinic and be encouraged to feed well balance diet.

The public service should add in its health talk programs the effects of malnutrition because malnutrition has effect on cognitive development and immune system impairment which may occur during pregnancy.

\section{Competing Interests}

The authors declare no conflict of interest in designing, conducting and reporting the findings of this work.

\section{References}

[1] Christian P, (2010). "Maternal height and risk of child mortality and under nutrition" 303: 1539-40 (PubMed).

[2] Amy L, Lisa Sacco, Adnan Hyder and Robert E. Black, (1990). "Malnutrition as an underlying cause of childhood deaths associated with infectious diseases in developing countries".

[3] Klein S, (2011). Protein energy malnutrition in: Goldman L, Schafer Al, eds. Goldman's Cecil medicine. $24^{\text {th }}$ ed Philadelphia, Pa: Saunders Elsevier; Chap 222.

[4] Department of health, (2011). A nutrition survey of preschool children. Report on health and social subjects, No.10. London: HMSO.

[5] Nelson, (2011). Textbook of Pediatrics, $19^{\text {th }}$ ed. Philadelphia: Saunders Elsevier: Chap 43.

[6] UNICEF, (1990). Malnutrition, UNICEF staff. working paper 7, (New York:).

[7] National Family Health Survey (NFHS) (1992-1993) "Infant feeding and child nutrition." \{Last retrieved on 2016 August $01\}$. Available from: htt://www.nfhsindia.org/india 1.html. 
[8] Pettetier and colleagues, (1990). "Surveying different types of malnutrition in children under 5years old in urban and rural areas, IRAN, Journal: PEJOUHANDEN WINTER 2001, volume, number 4 (20) pages 409 to $416 "$.

[9] Garcia and Alderman, (1990). "Rural and urban malnutrition related to gross national product per capital in developing countries".

[10] Hadelad L, Ruel MT, Garrett JL, (1999). “Are urban poverty and under nutrition growing. Some newly assembled evidence?" World development; 1891-904.
[11] Ngiange-B, Tumwaka. PM, Jacques Bo E, Kakhela. N and Francesco Pc, (2010). Malnutrition among children under the age of five: Dose geographic location matter? in the Democratic Republic of Congo.

[12] P, Gopalan HS, (2009). Under nutrition and risk of infection in preschool children. Indian J Med Res; 130: 579-83. (PubMed)

[13] Desphande J. D, Giri PA, Phalke DB, Phalke VD, Kalakoti P, Syed M, (2010). Socio cultural practices in relation to breast feeding, weaning and child rearing among Indian mothers and assessment of nutritional status of children under five in rural India" Australia's Med J.3:618-24. 